\title{
VALUE OF ENDOMETRIAL THICKNESS MEASUREMENT FOR DIAGNOSING ENDOMETRIAL HYPERPLASIA IN PERIMENOPAUSAL WOMEN
}

\section{Bishnu Prasad Das*}

Chintumoni Gogoi

\section{Professor, Obstetrics and Gynaecology department, Gauhati medical} college and Hospital, Guwahati, Assam, India. ${ }^{*}$ Corresponding Author

Post Graduate Trainee, Obstetrics and Gynaecology department, Gauhati medical college and Hospital, Guwahati, Assam, India.

ABSTRACT Objective- to determine the sonographic findings associated with endometrial hyperplasia (EH+) in perimenopausal women with abnormal uterine bleeding (AUB). Methods- $a$ retrospective study, in which 150 subjects, perimenopausal women with AUB, underwent transvaginal sonography (TVS) and endometrial biopsy. The TVS findings were evaluated with regard to $\mathrm{EH}+$. Result- Biopsy proven $\mathrm{EH}+$ was seen in $18.67 \%$ of subjects. EH+ was not found in any patient with TVS showing endometrial thickness $<8 \mathrm{~mm}$. Conclusion- There is a strong association between TVS endometrial thickness and endometrial biopsy findings. The risk of development of endometrial cancer is $29 \%$ in patients with complex atypical hyperplasia and $2 \%$ in patients with hyperplasia without atypia. Thus TVS should be in the first investigation in the management of AUB. Invasive method like dilatation and curettage (D\&C) to be considered in cases with endometrial thickness $>$ or $=8 \mathrm{~mm}$.

\section{KEYWORDS : endometrial thickness, endometrial hyperplasia, perimenopause}

\section{INTRODUCTION}

Endometrial cancer (EC) is common gynaecologic malignancy in western women. The worldwide incidence of endometrial cancer has risen over the last 20 years '. Increases in the rates of obesity and decreases in the rates of fertility suggest that the incidence of endometrial cancer will continue to increase in postmenopausal women, becoming a substantial public health problem worldwide ${ }^{2,3}$. This rise in its incidence has implications for both primary prevention and screening.

Endometrial hyperplasia $\left(\mathrm{EH}^{+}\right)$is a pathological condition characterised by hyperplastic changes in endometrial glandular and stromal structures lining the uterine cavity ${ }^{4}$. Most cases of $\mathrm{EH}^{+}$result from high levels of oestrogens, combined with insufficient levels of progesterone ${ }^{5,6}$. Unopposed oestrogenic stimulation of the endometrium causes proliferative glandular epithelial changes, including glandular remodelling, resulting in variably shaped, irregularly distributed glands. Risk factors for the development of EC include obesity, unbalanced oestrogen therapy, tamoxifen treatment, PCOS, and nulliparity ${ }^{7}$.

Endometrial hyperplasia is one of the most frequent causes of abnormal uterine bleeding, which leads to EC if left untreated. Abnormal uterine bleeding (AUB) is the commonest presenting symptom and major gynaecological problem responsible for about $70 \%$ of all gynaecologic out patients visits in the perimenopausal women. ${ }^{8}$ In 2001, the Stages of Reproductive Aging Workshop (STRAW) defined "perimenopause" as the period beginning with menopausal transition and ending 12 months after the last menstrual period. $^{9,10}$

Although irregular bleeding patterns are a normal and expected part of perimenopause, the incidence of uterine pathology and associated medical complication also increases in this age group. ${ }^{11}$

In the past, dilatation and curettage (D\&C) has been the method of choice for obtaining an endometrial sample; it is an invasive and blind procedure that may require the use of general anesthesia, so it is better to use safer and simpler investigation such as Transvaginal Sonography (TVS) or hysteroscopy. Since its introduction in the mid-1980s, TVS has become the standard way to image the female pelvis in the gynaecologic community. With its improved resolution, this technology is chosen by many instead of endometrial biopsy as a first-line tool to assess abnormal bleeding. If abnormal bleeding stems from myometrial pathology, sonography offers anatomy information regarding the myometrium that is not afforded by hysteroscopy or endometrial biopsy. In addition, TVS offers greater patient comfort and comparable detection of endometrial hyperplasia and cancer.

Many studies have validated the use of transvaginal ultrasonography (TVS) as the initial screening method for endometrial cancer ${ }^{12-15}$. Although an endometrial thickness (ET) of $\geq 5 \mathrm{~mm}$ is regarded as the cut-off value for postmenopausal women who present with vaginal bleeding, it warrants further investigation ${ }^{13}$. Furthermore, there is no established consensus on the ET threshold that distinguishes normal from malignant pathology in postmenopausal women without bleeding. Because the factors associated with a thickened endometrium in these women remain undetermined, the clinical management of women with an incidentally detected thickened endometrium has not been standardized or established.

This study was designed to evaluate the diagnostic value of ET as a predictor of endometrial carcinoma in perimenopausal women with AUB. The optimal cut-off values distinguishing between women with and without intrauterine pathologies were determined. The knowledge of these cut-off values may avoid the need to perform more invasive and unnecessary diagnostic tests, such as endometrial biopsy in cases where it is not indicated.

\section{Objectives of the Study}

1. To determine sonographic findings associated with endometrial hyperplasia in perimenopausal women with AUB.

2. To determine the efficacy of TVS to make preliminary diagnosis of $\mathrm{EH}^{+}$.

\section{MATERIALS AND METHODS}

This is an observational retrospective study including 100 perimenopausal women with AUB in GOPD, the department of obstetrics and gynaecology, Gauhati medical college and hospital from $1^{\text {st }}$ February, 2019 to $30^{\text {th }}$ November, 2019 over a period of 10 months. All patients provided written informed consent for the use of their data for research purposes. 
All data were collected from medical records. Patient characteristics taken into account were age (years), age at menarche (years), parity, body mass index (BMI), presence of hypertension or diabetes, menstrual cycle phase, family history of breast and colorectal cancer, current hormonal therapy (progestogen only, combined oral contraceptives, and vaginal ring), smoking habit, endometrial thickness $(\mathrm{mm})$, infertility,tamoxifen users, and duration of AUB (expressed in months from its beginning). Then we excluded women with fibroid uterus, IUCD, endocrine disorders, coagulation disorders, known cervical or uterine malignancy, on medications like cytotoxic agents, steroids, anticoagulants and neuroleptics.

We included all those perimenopausal women who had a definitive histological diagnosis of Endometrial hyperplasia (18.67\%) which we considered our reference standard. Histological diagnosis of endometrial hyperplasia $\left(\mathrm{EH}^{+}\right)$ refers to the WHO 2014 classifcation: atypical and nonatypical ${ }^{16}$.

All histopathological examinations, of endometrial sampling collected by $\mathrm{D} \& \mathrm{C}$, were performed by pathologists not involved and not blinded to the patients' pelvic ultrasonographic findings.

TVS was performed before D\&C procedure in all these women using ultrasonography machine Mindray Z6 and a vaginal probe V10 - 4BP to measure endometrial thickness.

\section{Results and Observations}

Of the 150 study women, 28 (18.67\%) were diagnosed with endometrial pathology $\left(\mathrm{EH}^{+}\right)$, and $122(81.3 \%)$ were assessed to have other pathology (proliferative, secretory, disordered, atrophic) based on the results of the final pathological analysis of the endometrial biopsy samples.

Of the 28 patients in the EH+ group, $12(42.8 \%)$ had simple hyperplasia without atypia; $9(32.1 \%)$ had complex hyperplasia without atypia ; 7 (25\%) had atypical complex hyperplasia.

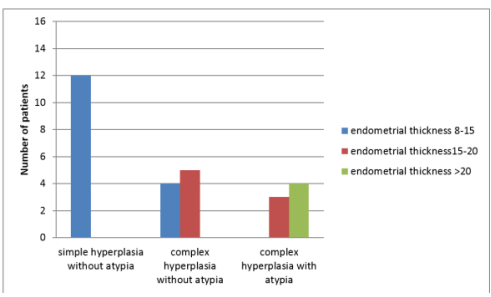

Fig 1: Graph showing comparison between endometrial thickness by TVS and types of endometrial hyperplasia

- In this study when endometrial thickness was $<4 \mathrm{~mm}$, no cases showed endometrial hyperplasia.

- When endometrial thickness is between 4-8mm, no cases showed endometrial hyperplasia.

- When endometrial thickness is between $8-15 \mathrm{~mm}, 25.8 \%$ cases showed endometrial hyperplasia.

- When endometrial thickness is between $15-20 \mathrm{~mm}, 34.7 \%$ cases showed endometrial hyperplasia.

- When the endometrial thickness is $\geq 20 \mathrm{~mm}, 50 \%$ cases showed endometrial hyperplasia.

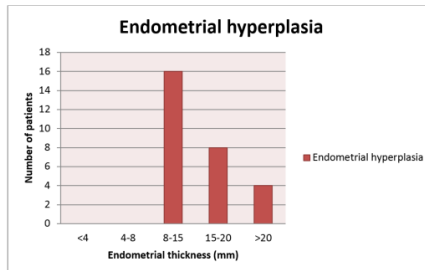

Fig 2: Graph Showing Correlation Between Endometrial Thickness And Endometrial Hyperplasia
Table 1: Correlation Of Endometrial Thickness With Endometrial Hyperplasia

\begin{tabular}{|c|c|c|c|}
\hline $\begin{array}{c}\text { Endometrial } \\
\text { thickness }(\mathrm{mm})\end{array}$ & $\begin{array}{c}\text { No. Of } \\
\text { patients }\end{array}$ & $\begin{array}{c}\text { ENDOMETRIAL } \\
\text { HYPERPLASIA }\end{array}$ & PERCENTAGE \\
\hline$<4$ & 10 & 0 & 0 \\
\hline $4-8$ & 47 & 0 & 0 \\
\hline $8-15$ & 62 & 16 & 25.8 \\
\hline $15-20$ & 23 & 8 & 34.7 \\
\hline$>20$ & 8 & 4 & 50 \\
\hline
\end{tabular}

The p value of the above table is 0.0002 and chi square value is 21.5 , which is highly significant. Thus the association between endometrial thickness and endometrial hyperplasia is highly significant.

With endometrial thickness $\geq 8 \mathrm{~mm}$, the specificity of TVS in detecting endometrial hyperplasia is $100 \%$ and positive predictive value is $100 \%$. p value is $<0.0001$ and chi square value is 17.543 , which is highly significant.

\section{DISCUSSION}

In the present study when endometrial thickness was < $8 \mathrm{~mm}$, no cases showed endometrial hyperplasia. All the 7 cases that showed major abnormality on histopathological evaluation i.e., complex hyperplasia with atypia had endometrial thickness $>15 \mathrm{~mm}$. With endometrial thickness $\geq 8 \mathrm{~mm}$, the specificity of TVS in detecting endometrial hyperplasia is $100 \%$ and positive predictive value is $100 \%$.

This study thus corroborated the findings of similar study done by Aliya Aslam et al. ${ }^{17}$ in 2009 . Their study found that no major endometrial pathology is detected when endometrial thickness is $<14 \mathrm{~mm}$. No significant pathological changes were detected by Acharya Veena et al. ${ }^{18}$ when endometrial thickness was $<14 \mathrm{~mm}$. Deshmukh V et al. ${ }^{19}$ concluded that pathological endometrium was not found on histopathological examination report in patients with endometrial thickness $<14.9 \mathrm{~mm}$. Study by Machado et $\mathrm{al}^{20}{ }^{20}$ in 2005 concluded that endometrial thickness less than 5 $\mathrm{mm}$ did not need $\mathrm{D} \& \mathrm{C}$ as none of these patients had atypia or malignancy which is also corroborated in the present study. The study by Chatapavit et al. ${ }^{21}$ concluded that endometrial thickness of $8 \mathrm{~mm}$ or less is less likely to be associated with malignant pathology in perimenopausal women with abnormal uterine bleeding. Shobhitha GL et $\mathrm{al}^{22}$ found sensitivity, specificity, NPV, PPV for TVS is $93.2 \%, 68.96 \%, 72.72 \%, 90.9 \%$ respectively in detecting endometrial hyperplasia with an endometrial thickness cut off of $8 \mathrm{~mm}$. ET $=8 \mathrm{~mm}$ with sensitivity of $83.6 \%$, specificity of $56.4 \%$ and NPV of $95.6 \%$ was proposed as the cut-off point for detection of the abnormal endometrium by Ozdemir et $\mathrm{al}^{23}$

\section{CONCLUSION}

Abnormal uterine bleeding is a common and sometimes a debilitating condition in peri-menopausal women. To establish specific diagnosis in the most efficient way, in a least invasive manner TVS is used as the initial screening method for endometrial pathology; it has replaced dilatation and curettage as the first-line investigation method for women with incidental vaginal bleeding and spotting. However, there is no consensus on the cut-off value for endometrial thickness for detecting the presence of any abnormality. No screening guidelines for pre- and peri-menopausal women who experience irregular menstruation.

In conclusion, TVS is useful for assessing endometrial pathology and diagnosing early endometrial cancer. Early detection of these conditions in patients with no specific symptoms (e.g., vaginal bleeding or spotting) can result in good patient outcomes. An ET of $\geq 8 \mathrm{~mm}$ was found to be the optimal cut-off value for detecting endometrial pathologies and cancers. Prospective studies with larger sample sizes are 
needed to confirm our findings.

\section{REFERENCES}

1. Von Gruenigen VE, Gil KM, Frasure HE, Jenison EL, Hopkins MP. The impact of obesity and age on quality of life in gynecologic surgery. Am J Obstet Gynecol 2005;193:1369-75.

2. Bray $F$ Dos Santos Silva I Moller H. Weiderpass E Endometrial cancer incidence trends in Europe: underlying determinants and prospects for prevention. Cancer Epidemiol Biomarkers Prev 2005; 14:1132-42.

3. Haslam DW, James WP. Obesity. Lancet 2005;366:1197-209.

4. Tavassoli F, Devilee P (eds.). World Health Organization Classification of Tumours. Pathology and Genetics. Tumours of the Breast and Female Genital Organs. IARC Press, Lyon 2003; 217-228.

5. Ricci E, Moroni S. Parazzini F, et al. Risk factors for endometrial hyperplasia: results from a case-control study. Int Gynecol Cancer 2002; 12: 257-260.

6. Reed SD, Newton KM, Clinton WL, et al. Incidence of endometrial hyperplasia. Am J Obstet Gynecol 2009; 200: 678.

7. Armstrong AJ, Hurd WW, Elguero $\mathrm{S}$, et al. Diagnosis and management of endometrial hyperplasia. J Minim Invasive Gynecol 2012; 19: 562-571

8. Grimes DA. Diagnostic dilatation and curettage: a reappraisal. Am J Obstet Gynecol. 1982;142(1):1-6.

9. Soules MR, Sherman S, Parrott E. Stages of reproductive aging workshop (STRAW). J. Womens Health, Gender Based Med. 2001;10:843-8. .

10. Awwad JT, Toth TL, Schiff I. Abnormal uterine bleeding in the perimenopause. Int J Fertil. and Menopausal Stud. 1993;38(5):261-9.

11. Speroff L, Fritz MA. Menopause and the perimenopausal transition, clinical endocrinology. In: Speroff L, Fritz MA, eds. Clinical gynecologic endocrinology and infertility. 7th ed. Philadelphia, London: Lippincott Williams \& Wilkins; 2005: 628

12. Fleischer AC, Wheeler JE, Lindsay I, Hendrix SL, Grabill S, Kravitz B, et al. An assessment of the value of ultrasonographic screening for endometrial disease in postmenopausal women without symptoms. Am J Obstet Gynecol 2001;184:70-5.

13. Karlsson B, Granberg S, Wikland M, Ylöstalo P Torvid K, Marsal K, et al. Transvaginal ultrasonography of the endometrium in women with postmenopausal bleeding--a Nordic multicenter study. Am J Obstet Gynecol 1995; 172:1488-94.

14. Gull B, Karlsson B, Milsom I, Granberg S. Can ultrasound replace dilation and curettage? A longitudinal evaluation of postmenopausal bleeding and transvaginal sonographic measurement of the endometrium as predictors of endometrial cancer. Am J Obstet Gynecol 2003;188:401-8.

15. Tsuda H, Nakamura H, Inoue T, Kawamura N, Adachi K, Bandera CA. Transvaginal ultrasonography of the endometrium in postmenopausal Japanese women. Gynecol Obstet Invest 2005;60:218-23

16. G. Emons, M. W. Beckmann, D. Schmidt, and P. Mallmann, "New WHO classifcation of endometrial hyperplasias,"Geburtshilfe und Frauenheilkunde, vol.75, no.2, pp.135-136,2015.

17. Aliya Aslam \& Ghazala. Role of TVS in cases of abnormal uterine bleeding, Professional Med. J. Janmarch 2009; (16) 1:127-34.

18. Acharya Veena, Mehta Seema, Randar Anita. Evaluation of dysfunctional uterine bleeding by TVS: Hysteroscopy and Histopathology. J Obstet Gynecol. 2003;53:170-77.

19. Deshmukh V, Yelikar KA, Davile M. Clinical Study Of Endometrial Pattern in Dysfunctional Uterine Bleeding by Transvaginal Sonography and It's Histopathological Correlation. Journal of Evolution of Medical and Dental Sciences. 2013 Apr 15;2(15):2440-6.

20. Machado LS, Mathew M, Al-Hassani A Vaclavinkova V. Correlation of endometrial thickness, cycle day and histopathology in women with abnormal uterine bleeding. Saudi Med J. 2005;26(2):260-263.

21. Getpook C., Wattanakumtornkul S. Endometrial thickness screening in premenopausal women with abnormal uterine bleeding. Journal of Obstetrics and Gynaecology Research. 2006:32:588-92

22. Shobhitha GL, Kumari VI, Priya PL, Sundari BT. Endometrial study bt TVS and it's correlation with histopathology in abnormal uterine bleeding. IOSR Journal of Dental and Medical Sciences. 2015 Apr;14 (4): $21-32$.

23. Özdemir S, Çelik Ç, Gezginç K, Kıreşi D, Esen H. Evaluation of endometrial thickness with transvaginal ultrasonography and histopathology in premenopausal women with abnormal vaginal bleeding. Arch Gynecol Obstet. 2010;282 (4):395-9. 